\title{
Mortality and Predictors of Mortality in Rheumatoid Arthritis - A Role for Mannose-binding Lectin?
}

\author{
LONE N. TROELSEN, PETER GARRED, and SØREN JACOBSEN
}

\begin{abstract}
Objective. Patients with rheumatoid arthritis (RA) have increased overall and cardiovascular mortality. Mannose-binding lectin (MBL) may play differentiated roles in the pathogenesis of RA. We had observed that high serum levels of MBL increased the risk of ischemic heart disease in patients with RA. In this followup study we describe the mortality in a cohort of 229 Danish patients with RA. We examine if previously reported factors and MBL influence the risk of overall death and death due to cardiovascular disease.

Methods. Known predictors of RA mortality were assessed. MBL extended genotypes (YA/YA, YA/XA, XA/XA, YA/YO, XA/YO, YO/YO) were determined; MBL serum concentrations were measured. The vital status and causes of death were assessed in a prospective study.

Results. The median followup was 10.3 years. The overall risk of death was $4 \%$ per year. Comparing mortality in the RA cohort with mortality in an age- and sex-matched cohort based on the general Danish population, we found significantly increased overall mortality [standardized mortality ratio (SMR) 1.5, 95\% CI 1.2-1.9, and cardiovascular mortality (SMR 1.7, 95\% CI 1.3-2.6)]. In multivariate analysis, significant predictors of overall death were extraarticular manifestations, positive rheumatoid factor, increased C-reactive protein (CRP), poor nutritional state, and serum MBL. Predictors of cardiovascular death were Health Assessment Questionnaire score, increased CRP, poor nutritional state, and the high-producing MBL genotype YA/YA.

Conclusion. Both overall and cardiovascular mortality were increased in Danish patients with RA. In our cohort, states of high MBL production and several previously reported factors contributed significantly to this increased risk of overall death and cardiovascular death. (First Release Feb 1 2010; J Rheumatol 2010;37:536-43; doi:10.3899/jrheum.090812)
\end{abstract}

Key Indexing Terms:

$\begin{array}{lrr}\text { ARTHRITIS } & \text { RHEUMATOID } & \text { MORTALITY } \\ \text { RISK FACTORS } & \text { CARDIOVASCULAR DISEASES } \\ \end{array}$

Studies concerning mortality in rheumatoid arthritis (RA) have been performed since the 1950s. A majority of these studies show an increased overall mortality in patients with RA compared to the general population, with standardized mortality ratios (SMR) of 1.2-1.3 in inception cohorts and 1.6-1.7 in noninception cohorts ${ }^{1}$. The causes of death are similar to those seen in the general population but with increased mortality rates from cardiovascular disease (CVD) and infection ${ }^{1,2}$. Most studies have not found excess in cancer deaths except from non-Hodgkin's lymphoma ${ }^{3}$.

From the Department of Rheumatology and the Laboratory of Molecular Medicine, Department of Clinical Immunology, Rigshospitalet,

Copenhagen University Hospital, Copenhagen, Denmark.

Supported by grants from the Danish Rheumatism Association, the Novo

Nordisk Research Foundation, the Capital Region of Denmark, and

Rigshospitalet, Copenhagen University Hospital.

L.N. Troelsen, MD, Department of Rheumatology and Department of Clinical Immunology; P. Garred, MD, DMSci, Laboratory of Molecular Medicine, Department of Clinical Immunology; S. Jacobsen, MD, DMSci, Department of Rheumatology, Rigshospitalet, Copenhagen University Hospital.

Address correspondence to Dr. L.N. Troelsen, Department of Rheumatology, Rigshospitalet, Copenhagen University Hospital, Blegdamsvej 9, DK-2100 Copenhagen, Denmark.E-mail: lone.troelsen@mail.dk

Accepted for publication October 9, 2009.
Predictive factors for overall mortality have been reported in many of the RA mortality studies. The predictive factors examined can be classified into 4 categories $^{1}$ : (1) nonmodifiable variables including demographic variables (age, sex), duration of disease, and genetic factors (e.g., major histocompatibility); (2) traditional clinical measures including radiographs, C-reactive protein (CRP), and rheumatoid factor (RF); (3) modifiable functional and global measures including physical function assessed by Health Assessment Questionnaire (HAQ) score; and (4) other potentially modifiable measures not specific for RA but important for outcomes including extraarticular status, body mass index, cigarette smoking, and comorbidity (e.g., diabetes and hypertension).

Fewer studies have examined the influence of drug therapy on RA survival. Steroid use was shown to both improve and reduce mortality ${ }^{4,5}$. Methotrexate (MTX) treatment is found to reduce total mortality and CVD mortality even after adjustment for potential confounders ${ }^{6}$. Different studies have reported increased survival due to treatment with other traditional disease-modifying antirheumatic drugs ${ }^{4,7}$, and most importantly, 2 recent studies indicated improved

See related editorial in this issue.

Personal non-commercial use only. The Journal of Rheumatology Copyright $@$ $~ 2010$. All rights reserved. 
mortality outcomes in patients with RA due to treatment with anti-tumor necrosis factor- $\alpha$ (anti-TNF- $\alpha$ ) agents ${ }^{8,9}$.

Mannose-binding lectin (MBL) is a C-type lectin involved in innate immune defense. It binds microorganisms and apoptotic cells through the carbohydrate recognition domain. Serum MBL can directly opsonize pathogens and enhance the activity of phagocytotic cells or it can activate complement through the lectin pathway. There is considerable variation in activating properties and plasma levels of MBL between individuals. This is caused by 3 different point mutations in exon 1 of the human MBL2 gene on chromosome $10^{10}$. The normal allele is named $\mathrm{A}$ and the common designation for the variant alleles is O. Moreover, polymorphisms in the promoter region of the MBL2 gene affect the expression of the protein ${ }^{11}$. Specifically, in an otherwise structurally normal MBL2 gene, the preservation of $\mathrm{G}$ at position -221 (termed promoter allele $\mathrm{Y}$ and resulting in haplotype YA) is associated with a high serum level of MBL.

The normal genotype and high serum levels of MBL have been associated with increased inflammation in late-onset and advanced $\mathrm{RA}^{12}$ and are shown to have a synovitis-enhancing effect in early anticyclic citrullinated peptide antibody-positive $\mathrm{RA}^{13}$. Recently we observed that genetically determined high serum levels of MBL increased the risk of myocardial infarction and ischemic heart disease in patients with $\mathrm{RA}^{14}$. However, MBL deficiency has been associated with erosive disease ${ }^{15,16}$, indicating that MBL may play differentiated roles in the pathogenesis of RA. The effect of MBL on RA mortality is not known.

Based on a followup study, we describe the mortality in a Danish cohort of 229 patients with RA. We examine whether known predictors of RA mortality and MBL have an influence on overall death and death due to CVD among these patients.

\section{MATERIALS AND METHODS}

Patients. The 229 patients all met 1987 American Rheumatism Association classification criteria ${ }^{17}$ for RA and originated from 2 study populations. Population 1 was 189 consecutive unrelated Caucasian Danish patients with RA (155 women, 34 men) who were included from September 1995 to December $1995^{12}$. Followup data were available for 183 of these patients and were included for analysis. Population 2 was 75 consecutive unrelated Caucasian Danish patients with early polyarthritis (61 women, 14 men) who were included from June 1996 to March $1998^{16}$. Forty-six patients fulfilled RA classification criteria. Followup data were available in all of these patients and included for analysis. Local scientific ethics committees approved both studies. All patients provided written informed consent.

Clinical and laboratory assessment at inclusion. Clinical and laboratory variables assessed at the time of inclusion included (1) sex; (2) age, and age at disease onset; (3) presence of erosive disease based on radiographs of hands and feet; (4) assessment of functional ability by HAQ score; (5) presence of extraarticular manifestations; (6) IgM RF in serum; (7) CRP in serum; and (8) presence of human leukocyte antigen (HLA)-DR1 and/or HLA-DR4.

Followup data. Clinical charts were used to collect information regarding other known predictive factors and treatment with MTX and anti-TNF- $\alpha$ drugs during followup. Based on self-reports, cigarette smoking status was determined as smoking (former and current) or not smoking (ever). Based on the latest physician's assessment, state of nutrition was recorded as poor (below normal), normal, or obese (beyond normal). Hypertension was defined as blood pressure $\geq 140 / 90 \mathrm{~mm} \mathrm{Hg}$ alone or in combination with the need for antihypertensive agents in the period of followup. Subjects were considered to have diabetes if the 1997 criteria of the American Diabetes Association were fulfilled ${ }^{18}$ or clinical charts reported a history of diabetes and treatment with insulin or antidiabetic drugs. Treatment status data for MTX and anti-TNF- $\alpha$ drugs were retrieved from clinical charts. However, use of various glucocorticosteroids, nonsteroidal antiinflammatory drugs (NSAID), acetylsalicylic acid (ASA), and statins was not consistently charted.

Outcome variables. The outcome variables of this study were the vital status and the causes of death. Using the patient's Central Person Register (CPR) number, the Danish Registry of Causes of Death provided information of vital status and death due to CVD, infection, and malignancy from the time of inclusion to December 31, 2006. Adverse outcomes were coded according to WHO ICD-10 codes (CVD: I00-I99; infection: A00-B99 and J10-J18; malignancy: C00-C99).

The CPR number is a unique identifier assigned to all living Danish citizens since 1968. The Danish Registry of Causes of Death is based on the CPR number and contains information such as date and place of death and classification of underlying and contributory causes of death. To further validate the outcome variables of this study, all diagnoses were verified by review of the clinical charts.

Genotyping and detection of serum mannose-binding lectin. Assessment of $M B L 2$ alleles and serum concentrations of MBL were carried out at the time of inclusion. Detection of $M B L 2$ alleles were analyzed as described ${ }^{11,12}$. All patients were genotyped for $M B L 2$ structural polymorphisms. Because of difficulties with polymerase chain reaction amplification, only 209 patients were genotyped for the promoter polymorphism in position $-221(\mathrm{X} / \mathrm{X}$, $\mathrm{X} / \mathrm{Y}, \mathrm{Y} / \mathrm{Y})^{12}$. Serum concentrations of MBL were measured in a double ELISA based on a monoclonal anti-MBL antibody ${ }^{19}$. Results from 23 sera were not reported because of technical difficulties ${ }^{12}$.

Statistical analysis. Mortality rates (total and cause-specific) were calculated by dividing the observed number of deaths by patient-years at risk. Patient-years of risk were estimated from time of enrollment to death or the end of followup, whichever came first. SMR were calculated by dividing the observed number of deaths by the expected number of deaths in an age-and sex-matched cohort based upon the general Danish population and representing the period of observation. The Danish Registry of Causes of Death provided the information of expected deaths. The $95 \%$ confidence intervals (CI) for the mortality rates and SMR were calculated by regarding the observed number of deaths as a Poisson variable and by looking up its 95\% interval in statistical tables.

Possible predictors of overall mortality and cardiovascular mortality. Risk of overall death and cardiovascular death according to $M B L 2$ extended genotypes (YA/YA, YA/XA, XA/XA, YA/YO, XA/YO, YO/YO) were initially examined using Kaplan-Meier survival plots displaying the cumulative survival function.

In a univariate Cox proportional-hazards regression analysis we examined the relation between previously reported predictors of RA mortality, the MBL2 genotype A/A, genotype YA/YA, serum levels of MBL, and the risk of overall death and cardiovascular death. Predictor variables that were significant, with a $\mathrm{p}$ value $<0.05$ in univariate analysis, were entered into a multivariable Cox proportional-hazards regression analysis, adjusting for sex and age at inclusion. The multivariable model was based on forward stepwise selection. It started with no variables and added significant variables $(\mathrm{p}<0.05)$ to the model until an extra variable was not statistically significant. The final model was re-run on the whole cohort, allowing patients to be added back in if they had no missing values in the final model. Hazard ratios (HR) were calculated. Statistical processing of the study was done using SPSS 15.

Personal non-commercial use only. The Journal of Rheumatology Copyright @ ${ }^{2010}$. All rights reserved. 


\section{RESULTS}

The median followup time in the 229 patients was 10.3 years, encompassing 2047 patient-years. The median duration of disease at enrollment was 6.3 years. Basic demographic, clinical, and serologic characteristics of the patients are shown in Table 1.

Mortality. The mortality rates and SMR are shown in Table 2 . The overall risk of death in the cohort was $4 \%$ per year. Comparing mortality in the RA cohort with mortality in an age- and sex-matched cohort based on the general Danish population, we found significantly increased overall mortality (SMR $1.5,95 \%$ CI 1.2-1.9) and cardiovascular mortality (SMR 1.9, 95\% CI 1.3-2.6) among the patients with RA. Mortality due to infectious diseases was also high in the patients with RA compared to the general Danish population, but statistically not significantly increased. Mortality due to malignancies overall was not increased.

Predictors of overall mortality and cardiovascular mortality. One hundred thirty-three patients $(58 \%)$ had genotype

Table 1. Demographic, clinical, and serological characteristics in a cohort of 229 patients with rheumatoid arthritis.

\begin{tabular}{|c|c|}
\hline Characteristic & \\
\hline \multicolumn{2}{|l|}{$\operatorname{Sex}(\%)$} \\
\hline Women & $187(82)$ \\
\hline Men & $42(18)$ \\
\hline Age at diagnosis, yrs, median (range) & $62(20-87)$ \\
\hline Duration of disease, yrs, median (range) & $6.3(0.1-54)$ \\
\hline Erosive disease, $\mathrm{n}(\%)$ & $160(70)$ \\
\hline HAQ score, median (range)* & $0.88(0-3.0)$ \\
\hline Extraarticular manifestations*, n (\%) & $34(16)$ \\
\hline IgM RF-positive*, n (\%) & $173(77)$ \\
\hline $\mathrm{CRP}>100 \mathrm{mg} / \mathrm{dl} *, \mathrm{n}(\%)$ & $123(56)$ \\
\hline HLA-DR1/HLA-DR4*, n (\%) & $164(74)$ \\
\hline Smoking*, n (\%) & $124(60)$ \\
\hline \multicolumn{2}{|l|}{ Nutrition*, n (\%) } \\
\hline Below normal & $36(17)$ \\
\hline Above normal & $61(28)$ \\
\hline Hypertension*, n (\%) & $54(24)$ \\
\hline Diabetes, n (\%) & $16(7.0)$ \\
\hline MTX treatment, n (\%) & $184(80)$ \\
\hline Anti-TNF- $\alpha$ drugs, $n(\%)$ & $31(14)$ \\
\hline
\end{tabular}

* Data not available on all patients. HAQ: Health Assessment Questionnaire; RF: rheumatoid factor; CRP: C-reactive protein; HLA: human leukocyte antigen; MTX: methotrexate; TNF- $\alpha$ : tumor necrosis factor- $\alpha$.
A/A, 82 (36\%) had genotype A/O, and 14 (6\%) had genotype $\mathrm{O} / \mathrm{O}$. Of the 209 patients tested for $M B L 2$ promoter allele $\mathrm{X} / \mathrm{Y}, 139$ (67\%) were homozygote for the functional allele $\mathrm{Y}$. The median serum concentration MBL was 0.93 $\mathrm{mg} / \mathrm{l}$ (range $0-7.8 \mathrm{mg} / \mathrm{l})$. The serum concentration of MBL varied with the $M B L 2$ genotypes and promoter genotypes as shown in Figure 1.

Kaplan-Meier survival plots of overall mortality and cardiovascular mortality according to MBL2 extended genotypes are shown in Figures 2 and 3. Genotypes associated with high serum levels of MBL (YA/YA, YA/XA, XA/XA) had excess overall mortality compared to genotypes associated with low serum levels of MBL (YA/YO, XA/YO, $\mathrm{YO} / \mathrm{YO}$ ), and the genotype $\mathrm{YA} / \mathrm{YA}$ was associated with the highest risk of cardiovascular death. In univariate Cox proportional-hazards regression analysis (Tables 3 and 4) we found that the $M B L 2$ genotype A/A conferred significantly increased risk of overall death compared to $M B L 2$ genotype $\mathrm{A} / \mathrm{O}+\mathrm{O} / \mathrm{O}(\mathrm{HR} 1.7 ; \mathrm{p}=0.02)$. The $M B L 2$ genotype YA/YA

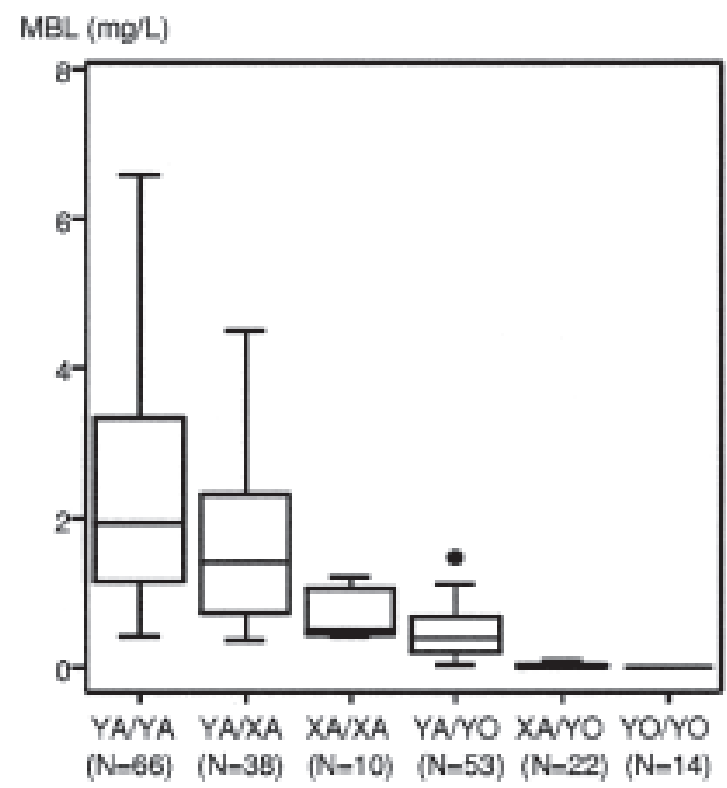

Figure 1. Serum concentrations of mannose-binding lectin (MBL) in relation to MBL2 extended genotypes in 203 patients with RA. Boxes represent 25 th to 75 th percentiles; lines within the boxes represent the median and outside the boxes, the 10th and 90th percentiles. Circles indicate outliers.

Table 2. Overall mortality and cause-specific mortality in 229 Danish patients with RA.

\begin{tabular}{lcccc}
\hline & $\begin{array}{c}\text { Expected No. } \\
\text { of Deaths }\end{array}$ & $\begin{array}{c}\text { Observed No. } \\
\text { of Deaths }\end{array}$ & $\begin{array}{c}\text { Mortality Rate, } \\
\% / \mathrm{yr}(95 \% \mathrm{CI})\end{array}$ & $\begin{array}{c}\text { Standardized Mortality } \\
\text { Ratio (95\% CI) }\end{array}$ \\
\hline $\begin{array}{l}\text { Causes of death } \\
\text { All causes }\end{array}$ & 54 & & & \\
$\quad$ Cardiovascular disease & 19 & 35 & $4.0(3.2-5.0)$ & $1.5(1.2-1.9)$ \\
Infection & 1.9 & 5 & $0.24(0.08-0.57)$ & $1.9(1.3-2.6)$ \\
Malignancy & 16 & 17 & $0.83(0.49-1.3)$ & $1.1(0.6-6.2)$ \\
Other & 17 & 25 & $1.2(0.79-1.8)$ & $1.4(0.9-2.2)$ \\
\hline
\end{tabular}




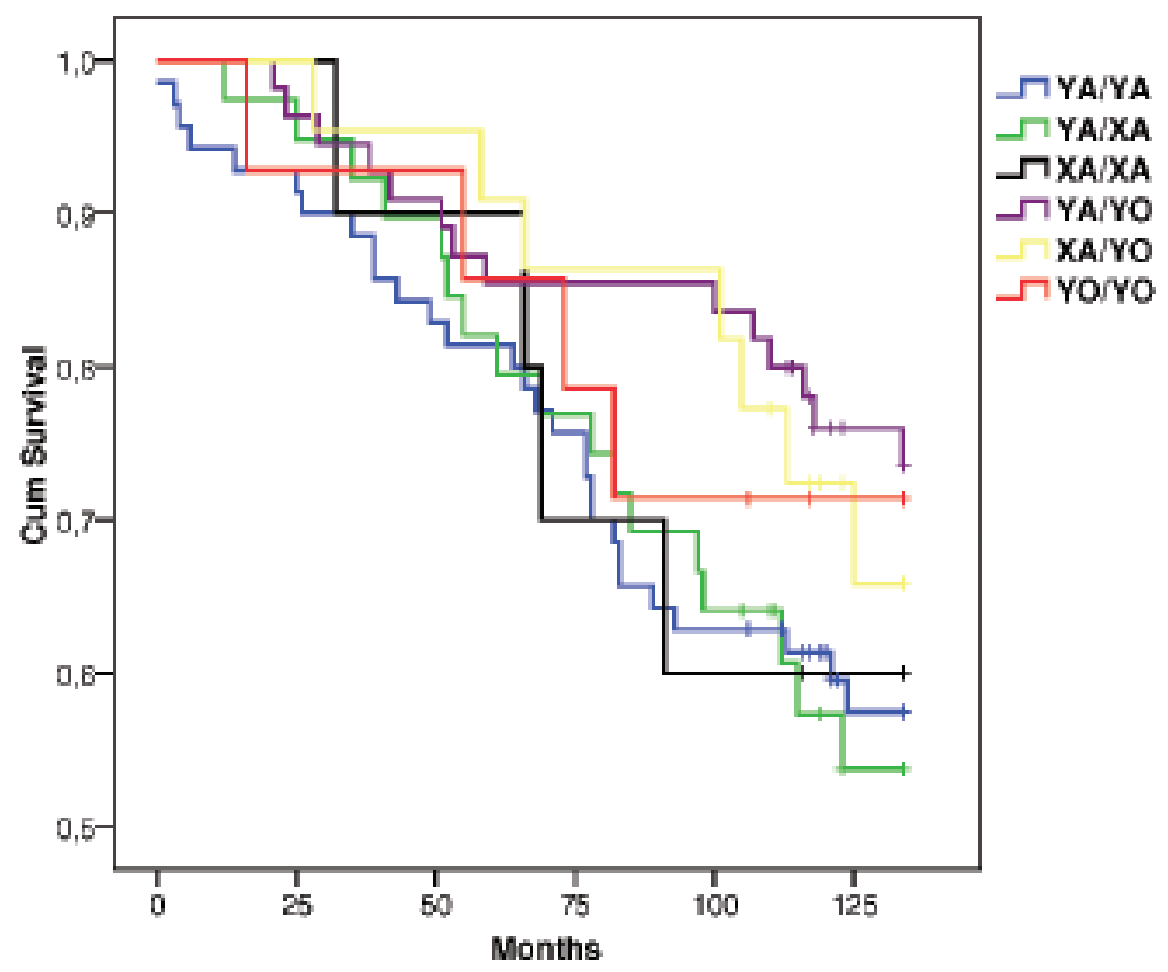

Figure 2. Overall survival according to mannose-binding lectin extended genotypes in 209 patients with RA.

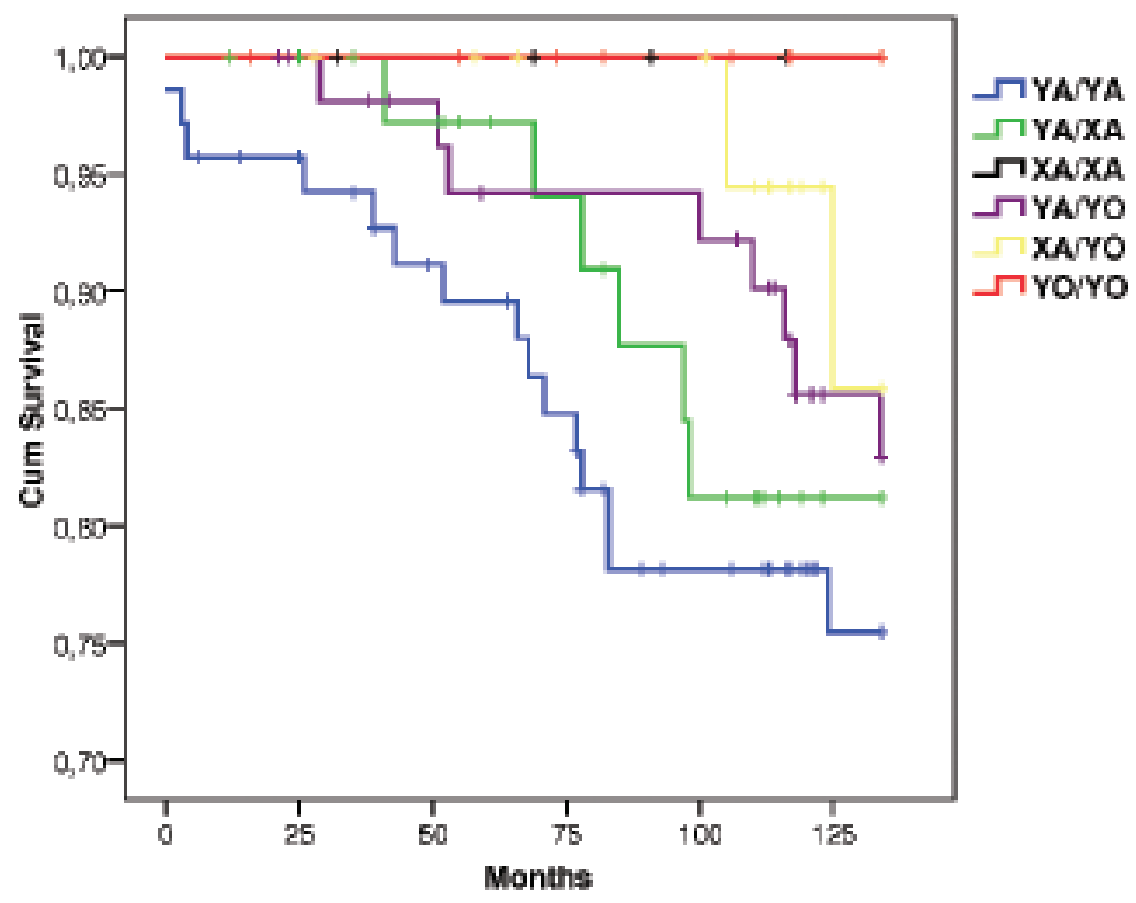

Figure 3. Cardiovascular survival according to mannose-binding lectin extended genotypes in 209 patients with RA. 
Table 3. Risk of overall death among patients with RA, according to known predictors and mannose-binding lectin. Univariate Cox proportional-hazards regression analysis.

\begin{tabular}{lcccc}
\hline Variables & $\mathrm{N}$ & $\mathrm{HR}$ & $95 \% \mathrm{CI}$ & $\mathrm{p}$ \\
\hline Duration of disease (decade) & 229 & 1.3 & $1.1-1.5$ & 0.004 \\
Erosive disease & 229 & 1.6 & $1.0-2.8$ & 0.07 \\
HAQ score & 224 & 1.5 & $1.1-2.1$ & 0.007 \\
Extraarticular manifestations & 219 & 2.2 & $1.3-3.7$ & 0.003 \\
IgM RF-positive & 224 & 2.1 & $1.1-3.9$ & 0.03 \\
CRP $>100$ mg/dl & 221 & 2.2 & $1.3-3.6$ & 0.002 \\
HLA-DR1/HLA-DR4 & 224 & 1.6 & $0.9-2.9$ & 0.09 \\
Smoking & 207 & 1.3 & $0.8-2.1$ & 0.25 \\
Nutrition below normal & 216 & 2.6 & $1.5-4.4$ & $<0.001$ \\
Nutrition above normal & 216 & 0.9 & $0.5-1.5$ & 0.61 \\
Hypertension & 227 & 0.9 & $0.5-1.5$ & 0.73 \\
Diabetes & 229 & 1.8 & $0.9-3.5$ & 0.11 \\
MTX treatment & 229 & 0.6 & $0.3-0.9$ & 0.02 \\
Anti-TNF- $\alpha$ drugs & 229 & 0.2 & $0.1-0.6$ & 0.004 \\
$M B L 2$ genotype A/A* & 229 & 1.7 & $1.1-2.8$ & 0.02 \\
$M B L 2$ genotype YA/YA** & 215 & 1.4 & $0.9-2.2$ & 0.143 \\
Serum MBL & 209 & 1.2 & $1.0-1.3$ & 0.02 \\
& & & & \\
\hline
\end{tabular}

* Comparing MBL2 genotype A/A with A/O + O/O. ** Comparing MBL2 genotype YA/YA with YA/XA + XA/XA + YA/O+ XA/O + O/O. HR: hazard ratio; HAQ: Health Assessment Questionnaire; RF: rheumatoid factor; CRP: C-reactive protein; HLA: human leukocyte antigen; MBL: mannose-binding lectin; MTX: methotrexate; TNF- $\alpha$ : tumor necrosis factor- $\alpha$.

Table 4. Risk of death due to cardiovascular disease among patients with RA, according to known predictors and mannose-binding lectin. Univariate Cox proportional hazards regression analysis.

\begin{tabular}{lllc}
\hline Variables & $\mathrm{N}$ & $\mathrm{HR}(95 \% \mathrm{CI})$ & $\mathrm{p}$ \\
\hline Duration of disease (decade) & 229 & $0.9(0.7-1.3)$ & 0.75 \\
Erosive disease & 229 & $1.3(0.6-2.8)$ & 0.49 \\
HAQ & 224 & $1.7(1.1-2.7)$ & 0.02 \\
Extraarticular manifestations & 219 & $1.4(0.6-3.4)$ & 0.46 \\
IgM RF-positive & 224 & $2.5(0.9-7.1)$ & 0.09 \\
CRP $>100$ mg/dl & 221 & $2.3(1.1-4.7)$ & 0.03 \\
HLA-DR1/HLA-DR4 & 224 & $1.7(0.7-4.2)$ & 0.22 \\
Smoking & 207 & $1.4(0.7-3.0)$ & 0.40 \\
Nutrition below normal & 216 & $2.5(1.1-5.7)$ & 0.03 \\
Nutrition above normal & 216 & $0.9(0.4-2.0)$ & 0.77 \\
Hypertension & 227 & $1.2(0.6-2.5)$ & 0.66 \\
Diabetes & 229 & $2.9(1.2-7.1)$ & 0.02 \\
MTX treatment & 229 & $0.8(0.3-1.8)$ & 0.53 \\
Anti-TNF- $\alpha$ drugs & 229 & $0.4(0.1-1.4)$ & 0.17 \\
$M B L 2$ genotype A/A* & 229 & $1.8(0.9-3.7)$ & 0.11 \\
$M B L 2$ genotype YA/YA** & 215 & $2.0(1.0-4.1)$ & 0.04 \\
Serum MBL & 209 & $1.3(1.0-1.5)$ & 0.02 \\
& & & \\
\hline
\end{tabular}

* Comparing MBL2 genotype A/A with A/O + O/O. ** Comparing MBL2 genotype YA/YA with YA/XA + XA/XA + YA/O+ XA/O + O/O. HR: hazard ratio; HAQ: Health Assessment Questionnaire; RF: rheumatoid factor; CRP: C-reactive protein; HLA: human leukocyte antigen; MBL: mannose-binding lectin; MTX: methotrexate; TNF- $\alpha$ : tumor necrosis factor- $\alpha$.

was associated with significantly increased risk of cardiovascular death compared with non-YA/YA genotypes (YA/XA, XA/XA, YA/YO, XA/YO, YO/YO) (HR 2.0; p =
0.04). Serum MBL was associated with significantly increased risk of both outcome variables (overall death: HR $1.2, \mathrm{p}=0.02$, and cardiovascular death: HR 1.3, $\mathrm{p}=0.02)$ in univariate analysis.

Regarding other predictors of mortality and cardiovascular mortality, we found that disease duration, HAQ score, extraarticular manifestations, positive IgM RF, CRP > 100 $\mathrm{mg} / \mathrm{dl}$, and poor state of nutrition conferred significantly increased risk of overall death in univariate analysis and that treatment with MTX and anti-TNF- $\alpha$ drugs conferred significantly reduced risk of overall death (Table 3 ). Significant predictors of cardiovascular mortality in univariate analysis were HAQ score, CRP > $100 \mathrm{mg} / \mathrm{dl}$, poor state of nutrition, and history of diabetes (Table 4).

Results of multivariable Cox proportional-hazards regression analysis adjusted for sex and age are shown in Tables 5 and 6. Significant predictors of overall death were extraarticular manifestations, positive IgM RF, CRP > 100 $\mathrm{mg} / \mathrm{dl}$, poor nutritional status, and serum MBL. Significant predictors of death due to CVD were HAQ score, CRP > $100 \mathrm{mg} / \mathrm{dl}$, poor state of nutrition, and the $M B L 2$ genotype YA/YA.

\section{DISCUSSION}

In our followup study, we found a 50\% increase in overall death and a near 2-fold increase in cardiovascular death among patients with RA compared with a sex- and age-matched Danish background population. Our study also indicated increased mortality due to infectious diseases, while mortality from malignancies was not increased among these patients with RA. Several known predictive factors were found to be associated with increased risk of total death and cardiovascular death. Moreover, higher serum levels of MBL were found to confer increased risk of overall death in both univariate and multivariable analysis, and the $M B L 2$ genotype YA/YA, which is associated with the

Table 5. Risk of overall death $(\mathrm{n}=55)$ among 177 patients with RA. Multivariate Cox proportional-hazards regression analysis based on forward stepwise selection and adjusted for sex and age at inclusion. Predictor variables included in the analysis were duration of disease (decade), HAQ score, extraarticular manifestations, positive IgM RF, CRP > $100 \mathrm{mg} / \mathrm{dl}$, state of nutrition below normal, treatment with MTX and anti-TNF- $\alpha$ drugs, MBL2 genotype A/A, and serum MBL. Patients with incomplete information on risk factors $(n=52)$ were not included in the analysis.

\begin{tabular}{lcc}
\hline Variables & HR $(95 \% \mathrm{CI})$ & $\mathrm{p}$ \\
\hline Extraarticular manifestations & $2.1(1.1-4.0)$ & 0.034 \\
IgM RF-positive & $2.9(1.3-6.4)$ & 0.008 \\
CRP > 100 mg/dl & $2.5(1.4-4.5)$ & 0.003 \\
Nutrition below normal & $2.3(1.2-4.2)$ & 0.008 \\
Serum MBL & $1.3(1.1-1.6)$ & 0.022 \\
\hline
\end{tabular}

HR: hazard ratio; RF: rheumatoid factor; CRP: C-reactive protein; MBL: mannose-binding lectin; HAQ: Health Assessment Questionnaire; MTX: methotrexate; TNF: tumor necrosis factor. 
Table 6. Risk of death due to cardiovascular disease $(n=26)$ among 190 patients with RA. Multivariate Cox proportional-hazards regression analysis based on forward stepwise selection and adjusted for sex and age at inclusion. Predictor variables included in the analysis were HAQ score, CRP $>100 \mathrm{mg} / \mathrm{dl}$, state of nutrition below normal, presence of diabetes, MBL2 genotype YA/YA, and serum MBL. Patients with incomplete information on risk factors $(n=39)$ were not included in the analysis.

\begin{tabular}{lcc}
\hline & HR $(95 \% \mathrm{CI})$ & $\mathrm{p}$ \\
\hline HAQ score & $2.1(1.2-3.7)$ & 0.015 \\
CRP $>100 \mathrm{mg} / \mathrm{dl}$ & $2.7(1.1-6.7)$ & 0.031 \\
Nutrition below normal & $3.6(1.4-8.9)$ & 0.007 \\
MBL2 genotype YA/YA & $2.7(1.2-5.9)$ & 0.016 \\
\hline
\end{tabular}

HR: hazard ratio; HAQ: Health Assessment Questionnaire; CRP: C-reactive protein; MBL: mannose-binding lectin.

highest serum concentrations of MBL, was associated with increased risk of cardiovascular death in univariate as well as multivariable analysis.

RA mortality and predictors of premature mortality in patients with RA have been examined in several studies. In a recent review including 124 studies of RA mortality and 53 studies concerning predictors of RA mortality, an aggregate overall SMR of 1.5-1.6 was observed ${ }^{1}$. In our study, the overall SMR was 1.5 , reflecting a mortality in our Danish RA cohort similar to that in other RA populations.

Several predictors of RA mortality have been reported. Except for older age and sex, the most significant predictors are comorbidities, patient and physician global estimates, and poor functional status ${ }^{1}$. In our study, physical function measured by HAQ score conferred significantly increased risk of overall death in univariate analysis but not in multivariable analysis. Unfortunately, we did not have consistent information on comorbidities and patient and physician global estimates, as this trial was not originally designed as a study of mortality outcomes. The best predictors of overall death were extraarticular manifestations, presence of IgM RF, CRP above the normal range, poor state of nutrition, and increasing levels of serum MBL.

In our study, consistent information on glucocorticosteroids and NSAID was missing, but complete data on treatment with MTX and anti-TNF- $\alpha$ drugs were available. Earlier studies have shown that treatment with MTX can reduce overall mortality and CVD mortality among patients with $\mathrm{RA}^{6}$ and treatment with anti-TNF- $\alpha$ drugs also seems to have a positive effect on RA mortality ${ }^{8,9}$. We found that treatment with MTX and anti-TNF- $\alpha$ drugs significantly reduced risk of overall death in univariate analysis, which reflects these prior findings.

Most recently, studies have found that the age- and sexadjusted rate of cardiovascular mortality in patients with RA is $50 \%-100 \%$ higher than in the general population ${ }^{4,20}$. The SMR for CVD in our study was 1.9 , which corroborates these earlier observations. Except for presence of diabetes, which was associated with increased cardiovascular mortal- ity in univariate analysis, none of the known traditional CVD risk factors assessed (smoking, state of nutrition beyond normal, or hypertension) conferred additional risk of cardiovascular death in this cohort. However, because of the original design of the study, we did not have information concerning lipid status and body mass index. Another limitation in the analysis of cardiovascular death was the relatively small number of events and the lack of systematic recording of treatment with glucocorticosteroids, NSAID, ASA, and statins. Several proatherosclerotic effects of corticosteroids have been described, but it has also been suggested that the antiinflammatory effects of corticosteroids may balance out their adverse cardiovascular effects, thus reducing the risk of accelerated atherosclerosis in $\mathrm{RA}^{21}$. A recent study showed that the risk of myocardial infarction and death was associated with use of NSAID among healthy individuals $^{22}$. However, the risk ratios were relatively small and the population source consisted of more than 4 million individuals, indicating that large trials would be needed to corroborate these findings in patients with RA. Treatment with statins may reduce the risk of CVD in patients with RA. Statins generally have positive effects on lipid levels and treatment with atorvastatin is shown to have antiinflammatory effects in $\mathrm{RA}^{23}$.

Despite these limitations, we found that markers of acute inflammation (CRP above the normal range) and chronic inflammatory damage (increasing HAQ score) conferred increased risk of cardiovascular death. This is in line with findings in other studies in which systemic inflammation and disease severity are associated with increased risk of CVD $^{24,25}$, and the observation that CVD in patients with RA cannot be fully explained by an excess of traditional cardiovascular risk factors ${ }^{26,27}$. Moreover, as reported ${ }^{28}$, we found cachexia to be a major risk factor for cardiovascular mortality in RA.

Recently we observed that high serum levels of MBL increase the risk of myocardial infarction and ischemic heart disease in $\mathrm{RA}^{14}$. Our finding that the MBL2 genotype YA/YA confers significantly increased risk of death due to CVD may reflect this prior observation. However, increasing serum levels of MBL were also associated with an additional risk of overall death, indicating that high serum levels of MBL may confer a disadvantage in other comorbidities, causing excess mortality in RA. We were not able to examine whether MBL2 genotypes or serum levels of MBL were associated with increased risk of death due to infectious diseases or other non-CVD because the number of patients in the study was limited.

The normal MBL2 genotype and high serum levels of MBL are associated with increased disease activity and physical disability in $\mathrm{RA}^{12,13}$, and high serum levels of MBL are a significant predictor of mortality in diabetes ${ }^{29}$. $M B L 2$ genotypes resulting in low MBL serum concentrations confer advantages in primary Sjögren's syndrome ${ }^{30}$

Personal non-commercial use only. The Journal of Rheumatology Copyright (c) 2010. All rights reserved. 
and intracellular infections such as tuberculosis ${ }^{31}$, visceral leishmaniasis ${ }^{32}$, and human immunodeficiency virus ${ }^{33}$. Several pathophysiological mechanisms have been discussed in relation to these findings and it has been suggested that MBL, through binding to pathogens and circulating immune complexes as well as dying host cells and cellular debris, mediates complement activation through the lectin pathway, resulting in excess inflammation and increased incidence of clinical complications.

We found that overall mortality and cardiovascular mortality were increased in Danish patients with RA. Further, several previously reported factors and states of high MBL production conferred a significantly increased risk of overall death and cardiovascular death. Future studies should focus on the role of MBL as a possible predictor of RA mortality and whether our findings may be applicable beyond RA.

\section{REFERENCES}

1. Sokka T, Abelson B, Pincus T. Mortality in rheumatoid arthritis: 2008 update. Clin Exp Rheumatol 2008;26 Suppl 51:35-61.

2. Naz SM, Symmons DP. Mortality in established rheumatoid arthritis. Best Pract Res Clin Rheumatol 2007;21:871-83.

3. Symmons DP, Jones MA, Scott DL, Prior P. Longterm mortality outcome in patients with rheumatoid arthritis: early presenters continue to do well. J Rheumatol 1998;25:1072-7.

4. Wallberg-Jonsson S, Ohman ML, Dahlqvist SR. Cardiovascular morbidity and mortality in patients with seropositive rheumatoid arthritis in northern Sweden. J Rheumatol 1997;24:445-51.

5. Wolfe F, Mitchell DM, Sibley JT, Fries JF, Bloch DA, Williams CA, et al. The mortality of rheumatoid arthritis. Arthritis Rheum 1994;37:481-94.

6. Choi HK, Hernan MA, Seeger JD, Robins JM, Wolfe F. Methotrexate and mortality in patients with rheumatoid arthritis: a prospective study. Lancet 2002;359:1173-7.

7. Lehtinen $\mathrm{K}$, Isomaki $\mathrm{H}$. Intramuscular gold therapy is associated with long survival in patients with rheumatoid arthritis. J Rheumatol 1991;18:524-9.

8. Carmona L, Descalzo MA, Perez-Pampin E, Ruiz-Montesinos D, Erra A, Cobo T, et al. All-cause and cause-specific mortality in rheumatoid arthritis are not greater than expected when treated with tumour necrosis factor antagonists. Ann Rheum Dis 2007;66:880-5.

9. Jacobsson LT, Turesson C, Nilsson JA, Petersson IF, Lindqvist E, Saxne T, et al. Treatment with TNF blockers and mortality risk in patients with rheumatoid arthritis. Ann Rheum Dis 2007;66:670-5.

10. Garred P, Larsen F, Madsen HO, Koch C. Mannose-binding lectin deficiency - revisited. Mol Immunol 2003;40:73-84.

11. Madsen HO, Garred P, Thiel S, Kurtzhals JAL, Lamm LU, Ryder LP, et al. Interplay between promoter and structural gene variants control basal serum level of mannan-binding protein. J Immunol 1995; 155:3013-20

12. Garred P, Madsen HO, Marquart H, Hansen TM, Sorensen SF, Petersen J, et al. Two edged role of mannose binding lectin in rheumatoid arthritis: a cross sectional study. J Rheumatol 2000;27:26-34

13. Jacobsen S, Garred P, Madsen HO, Heegaard NH, Hetland ML, Stengaard-Pedersen K, et al. Mannose-binding lectin gene polymorphisms are associated with disease activity and physical disability in untreated, anti-cyclic citrullinated peptide-positive patients with early rheumatoid arthritis. J Rheumatol 2009;36:731-5
14. Troelsen LN, Garred P, Madsen HO, Jacobsen S. Genetically determined high serum levels of mannose-binding lectin and agalactosyl $\operatorname{IgG}$ are associated with ischemic heart disease in rheumatoid arthritis. Arthritis Rheum 2007;56:21-9.

15. Graudal NA, Madsen HO, Tarp U, Svejgaard A, Jurik AG, Graudal $\mathrm{HK}$, et al. The association of variant mannose-binding lectin genotypes with radiographic outcome in rheumatoid arthritis. Arthritis Rheum 2000;43:515-21.

16. Jacobsen S, Madsen HO, Klarlund M, Jensen T, Skjodt H, Jensen $\mathrm{KE}$, et al. The influence of mannose binding lectin polymorphisms on disease outcome in early polyarthritis. J Rheumatol 2001;28:935-42.

17. Arnett FC, Edworthy SM, Bloch DA, McShane DJ, Fries JF, Cooper NS, et al. The American Rheumatism Association 1987 revised criteria for the classification of rheumatoid arthritis. Arthritis Rheum 1988;31:315-24.

18. Gavin JR, Alberti KGMM, Davidson MB, DeFronzo RA, Drash A Gabbe SG, et al. Report of the expert committee on the diagnosis and classification of diabetes mellitus. Diabetes Care 1997;20:1183-97.

19. Garred P, Madsen HO, Kurtzhals JAL, Lamm LU, Thiel S, Hey AS, et al. Diallelic polymorphism may explain variations of the blood-concentration of mannan-binding protein in Eskimos, but not in black Africans. Eur J Immunogenet 1992;19:403-12.

20. Goodson N, Marks J, Lunt M, Symmons D. Cardiovascular admissions and mortality in an inception cohort of patients with rheumatoid arthritis with onset in the 1980s and 1990s. Ann Rheum Dis 2005;64:1595-601.

21. Davis JM, Maradit-Kremers H, Gabriel SE. Use of low-dose glucocorticoids and the risk of cardiovascular morbidity in rheumatoid arthritis: What is the true direction of effect? J Rheumatol 2005;32:1856-62.

22. Fosbol EL, Gislason GH, Jacobsen S, Folke F, Hansen ML, Schramm TK, et al. Risk of myocardial infarction and death associated with the use of nonsteroidal anti-inflammatory drugs (NSAIDs) among healthy individuals: a nationwide cohort study. Clin Pharmacol Ther 2009;85:190-7.

23. McCarey DW, McInnes LB, Madhok R, Hampson R, Scherbakova O, Ford I, et al. Trial of Atorvastatin in Rheumatoid Arthritis (TARA): double-blind, randomised placebo-controlled trial. Lancet 2004;363:2015-21.

24. Maradit-Kremers H, Nicola PJ, Crowson CS, Ballman KV, Gabriel SE. Cardiovascular death in rheumatoid arthritis: a population-based study. Arthritis Rheum 2005;52:722-32

25. Wallberg-Jonsson S, Johansson H, Ohman ML, Rantapaa-Dahlqvist S. Extent of inflammation predicts cardiovascular disease and overall mortality in seropositive rheumatoid arthritis. A retrospective cohort study from disease onset. J Rheumatol 1999;26:2562-71

26. Del Rincon I, Williams K, Stern MP, Freeman GL, Escalante A. High incidence of cardiovascular events in a rheumatoid arthritis cohort not explained by traditional cardiac risk factors. Arthritis Rheum 2001;44:2737-45.

27. Dessein PH, Joffe BI, Veller MG, Stevens BA, Tobias M, Reddi K et al. Traditional and nontraditional cardiovascular risk factors are associated with atherosclerosis in rheumatoid arthritis. J Rheumatol 2005;32:435-42.

28. Kremers HM, Nicola PJ, Crowson CS, Ballman KV, Gabriel SE. Prognostic importance of low body mass index in relation to cardiovascular mortality in rheumatoid arthritis. Arthritis Rheum 2004;50:3450-7.

29. Hansen TK, Gall MA, Tarnow L, Thiel S, Stehouwer CD, Schalkwijk CG, et al. Mannose-binding lectin and mortality in type 2 diabetes. Arch Intern Med 2006;166:2007-13.

30. Ramos-Casals M, Brito-Zeron P, Soria N, Nardi N, Vargas A, 
Munoz S, et al. Mannose-binding lectin-low genotypes are associated with milder systemic and immunological disease expression in primary Sjogren's syndrome. Rheumatology 2009;48:65-9.

31. Soborg C, Madsen HO, Andersen AB, Lillebaek T, Kok-Jensen A, Garred P. Mannose-binding lectin polymorphisms in clinical tuberculosis. J Infect Dis 2003;188:777-82.
32. Alonso DP, Ferreira AF, Ribolla PE, de Miranda Santos IK, do Socorro Pires e Cruz M, Aécio de Carvalho F, et al. Genotypes of the mannan-binding lectin gene and susceptibility to visceral leishmaniasis and clinical complications. J Infect Dis 2007;195:1212-7.

33. Dzwonek A, Novelli V, Bajaj-Elliott M, Turner M, Clapson M, Klein N. Mannose-binding lectin in susceptibility and progression of HIV-1 infection in children. Antivir Ther 2006;11:499-505. 